\title{
Hearing Aid-Related Standards and Test Systems
}

\author{
Gert Ravn, B.Sc. ${ }^{1}$ and David Preves, Ph.D. ${ }^{2}$
}

\section{ABSTRACT}

Many documents describe standardized methods and standard equipment requirements in the field of audiology and hearing aids. These standards will ensure a uniform level and a high quality of both the methods and equipment used in audiological work. The standards create the basis for measuring performance in a reproducible manner and independent from how and when and by whom parameters have been measured. This article explains, and focuses on, relevant acoustic and electromagnetic compatibility parameters and describes several test systems available.

KEYWORDS: Standards, hearing aids, reproducible measures, performance criteria, pure tone measures, speech gain measures, International Electrotechnical Commission/American National Standards Institute harmonization, electromagnetic compatibility

Learning Outcomes: As a result of this activity, the participant will be able to describe what hearing aid standards actually standardize and list at least three uses of hearing aid standards.

Historically, hearing aid manufacturers have made measurements of hearing aid performance and reported them on specification sheets using procedures specific to that manufacturer. These measurements are needed so that electroacoustic data can be provided to hearing aid dispensing professionals, as well as to inform government agencies about both quality control and actual performance during use. In the past, it was difficult for the hearing health professionals who used these specification sheets to assess and compare hearing aid performance across manufacturers, because their measurements were done differently. Standardizing the methodology for obtaining theses data ensures that consistent procedures are readily available, understandable, and replicable for those needing to use this information.
${ }^{1}$ Danish Electronic Light and Acoustics, Hørsholm, Denmark; ${ }^{2}$ Starkey Hearing Technologies, Eden Prairie, Minnesota.

Address for correspondence: Gert Ravn, B.Sc., Danish Electronic Light and Acoustics, Venlighedsvej 4, 2970 Hørsholm, Denmark (e-mail: ger@delta.dk).
Standardization and Calibration Part 2: Brief Stimuli, Immittance, Amplification, and Vestibular Assessment; Guest Editor, Robert Burkard, Ph.D.

Semin Hear 2015;36:29-48. Copyright (C) 2015 by Thieme Medical Publishers, Inc., 333 Seventh Avenue, New York, NY 10001, USA. Tel: +1(212) 584-4662. DOI: http://dx.doi.org/10.1055/s-0034-1396925. ISSN 0734-0451. 
Hearing aid performance data of interest includes, but is not limited to, measurements of the amount of amplification, frequency response, distortion, internal noise, current drain, telecoil sensitivity, directionality, and automatic gain control.

American National Standards Institute (ANSI) and International Electrotechnical Commission (IEC) hearing aid-related standards fill the need for specifying consistent methods to measure and verify the performance of systems and devices. The purpose of these standards is to ensure that the same measurements made on a hearing aid at different facilities using different test equipment, but following the procedures described in the standards and using equipment complying with these requirements, give substantially the same results. Efforts for standardizing measurement procedures to assess hearing aid performance parameters were underway as early as 1935. ${ }^{1}$ Standardized measurement procedures are achieved by consensus and are typically a result of widely used practices by those in the field.

In this article, we will explore briefly the process of developing standards for making these measurements and review the scope and content of some of the hearing aid-related standards and recent activities in the standards working groups (WGs) that formulate them. Examples of hearing aid test equipment that perform these measurements are provided, and calibration procedures for this equipment are discussed.

\section{HEARING AID FEATURES AND THE NEED FOR PERFORMANCE MEASUREMENT STANDARDS}

Due to advances in hearing aid technology and the introduction of new features, methodology used in performance test standards may become outdated. Many years ago, compression or automatic gain control in hearing aids was one of the first features incorporated in hearing aids that required performance standardization to assess a temporally varying process. Some comparatively recent features include adaptive directionality, noise management, environmental detection, feedback cancellation, and fre- quency transposition. These processingintensive features are adaptive in nature, resulting in the processing they perform on hearing aid input signals to change over time. Only a few available performance measurement standards assess performance of these adaptive features.

\section{THE STANDARDS DEVELOPMENT PROCESS}

After the need has arisen for standardization of some aspect of hearing aid performance, a new standards committee is established or an existing standards committee is identified to work on drafting a new standard or updating an existing standard. Experts in the technology area involved are invited to participate. Ideally, these experts should have financial support to participate in standards drafting and reviewing efforts and numerous meetings, many of which may occur by necessity during their spare time. With few exceptions, there is no external funding from standards organizations for people who participate in standard committees, and many tasks and activities may be accomplished by committee members in after-hours work.

ANSI standards are typically reaffirmed, revised, or withdrawn every 5 years. Existing standards are not modified to bring them in line with changes in technology and currently used measurement procedures. Instead, existing standards being modified undergo the same consensus and approval process that occurs when formulating a new standard, first requiring consensus approval by members of the WG, and then approval by balloting members and individual experts of the parent Acoustical Society of America (ASA) committee. For hearing aid-related standards, the parent committee is ASA Accredited Standards Committee S3 on Bioacoustics. Negative votes and comments resulting from the ballot or public comment must be resolved by the WG, and the revised draft is circulated for final approval by the parent committee and a call for public comments is published again. Then the new or revised standard is sent to ANSI for final approval and publication as an American National Standard. 


\section{ANSI AND/OR IEC HEARING AID- RELATED STANDARDS}

Performing procedures described in standards are normally not required by law unless they are adopted by a regulatory agency-for example, the Food and Drug Administration (FDA) made testing and expressing hearing aid performance (as specified in ANSI S3.22 2014) a quality control requirement in order for a manufacturer to be able to sell hearing aids in the United States. Likewise, several IEC 60118 standards have been adopted for homologation purposes by regulatory authorities in several European countries to qualify hearing aids for sale in those countries.

In the past, WGs that formulate ANSI and IEC hearing aid-related standards have not always worked together to achieve harmonized standards. ${ }^{2}$ The result has been the publication of separate ANSI and IEC hearing aid-related standards that cover the same topics, which puts a greater burden on test equipment and hearing aid manufacturers that must perform similar, but different, tests. However, recently there has been a greater effort within ANSI and IEC hearing aidrelated standards committees to achieve as much harmonization as possible. A description of harmonization can be found in Wilber, Laukli, and Burkard in this volume.

The following sections review some of the more relevant ANSI and IEC standards, grouped by the signals they utilize and what they test. Standards relevant to hearing aids and hearing aid test systems can be found in Tables 1 and 2 .

\section{TESTING WITH PURE TONES}

- ANSI S3.22 (2014), IEC 60118-7 (2005), and IEC 60118-0 (1994)

These standards contain electroacoustic tests for characterizing the performance and for assessing the reliability of air conduction hearing aids based on controlling sound pressure levels at the hearing aid microphone inlet and measuring hearing aid output with an acoustic coupler or an ear simulator. Some of the test results are toleranced for quality control and type-testing purposes and for use in manufacturer data sheets.

Because they include tolerances, the methods and equipment used in these standards were selected to be straightforward to implement and reproducible across different test facilities. Before the procedures in many of these standards were first published (e.g., ANSI S3.22 [2014]), their measurement reproducibility was first validated by round-robin testing within standards WGs.

The ANSI S3.22 (2014) and IEC 60118-7 (2005) standards utilize a $2-\mathrm{cm}^{3}$ acoustic coupler, which is intended only for loading a hearing aid with a specified acoustic impedance and not to model the sound pressure in a person's ear $\left(2 \mathrm{~cm}^{3}\right.$ is the average estimated residual volume between the tip of the earmold, or ITE-type hearing aid, and the eardrum). The test results obtained by the methods incorporated in these standards express the performance under the specific conditions of the test and may deviate substantially from the performance of the hearing aid under actual use conditions. Use of the $2-\mathrm{cm}^{3}$ acoustic coupler also produces different results than those obtained with the occluded ear simulator specified in ANSI S3.25 (2009) and IEC 60318-4 (2010). For example, frequency response measures made with an ear simulator have a higher output sound pressure level (SPL) than those obtained with a $2-\mathrm{cm}^{3}$ coupler. $^{3}$

Currently, ANSI S3.22 (2014) and IEC 60118-7 (2005) are fairly well harmonized (i.e., they are largely technically equivalent); the main differences are the telecoil tests in the bodies of the standards: ANSI S3.22 (2014) uses the Telephone Magnetic Field Simulator (TMFS) fixture to simulate the magnetic field produced by a telephone handset, whereas IEC 60118-7 (2005) specifies an induction loop test in a vertical magnetic field only and does not use the TMFS because most applications for telecoils in countries outside the United States involve picking up inductive room loop signals, rather than inductive signals from a telephone. However, currently IEC 60118-0 (1994) is being modified to be more aligned with ANSI S3.22 (2014), specifying many of the quality control tests included in IEC 60118-7 (2005) requiring use of the $2-\mathrm{cm}^{3}$ coupler, 


\section{Table 1 IEC/ISO Standards Relevant to Hearing Aids and Hearing Aid Test Systems}

\begin{tabular}{|c|c|}
\hline IEC 60118-0 1994 & $\begin{array}{l}\text { Electroacoustics-Hearing aids_Part 0: Measurement of the performance } \\
\text { characteristics }\end{array}$ \\
\hline IEC 60118-1 1999 & $\begin{array}{l}\text { Electroacoustics-Hearing aids_-Part 1: Hearing aids with induction pick-up } \\
\text { coil input }\end{array}$ \\
\hline IEC 60118-2 1996 & $\begin{array}{l}\text { Electroacoustics-Hearing aids_-Part 2: Hearing aids with automatic gain } \\
\text { control circuits }\end{array}$ \\
\hline IEC 60118-4 2006 & $\begin{array}{l}\text { Electroacoustics_-Hearing aids_-Part 4: Induction loop systems for hearing } \\
\text { aids_-Magnetic field strength—System performance requirements }\end{array}$ \\
\hline IEC 60118-5 1983 & Electroacoustics—Hearing aids_-Part 5: Nipples for insert earphones \\
\hline IEC 60118-6 1999 & $\begin{array}{l}\text { Electroacoustics-Hearing aids-Part 6: Characteristics of electrical input } \\
\text { circuits for hearing aids }\end{array}$ \\
\hline IEC 60118-7 2005 & $\begin{array}{l}\text { Electroacoustics-Hearing aids_-Part 7: Measurement of the performance } \\
\text { characteristics of hearing aids for production, supply, and delivery quality } \\
\text { assurance purposes }\end{array}$ \\
\hline IEC 60118-8 2005 & $\begin{array}{l}\text { Electroacoustics-Hearing aids-Part 8: Methods of measurement of perfor- } \\
\text { mance characteristics of hearing aids during simulated in situ working } \\
\text { conditions }\end{array}$ \\
\hline IEC 60118-9 1985 & $\begin{array}{l}\text { Electroacoustics-Hearing aids-Part 9: Methods of measurement of charac- } \\
\text { teristics of hearing aids with bone vibrator output }\end{array}$ \\
\hline IEC 60118-12 1997 & $\begin{array}{l}\text { Electroacoustics-Hearing aids-Part 12: Dimensions of electrical connector } \\
\text { systems }\end{array}$ \\
\hline IEC 60118-13 2011 & Electroacoustics—Hearing aids_-Part 13: Electromagnetic compatibility \\
\hline IEC 60118-14 1998 & Electroacoustics-Hearing aids-Part 14: Specification of a digital interface \\
\hline IEC 60118-15 2012 & $\begin{array}{l}\text { Electroacoustics-Hearing aids_-Part 15: Methods for characterizing signal } \\
\text { processing in hearing aids with a speechlike signal }\end{array}$ \\
\hline IEC 60318-5 2006 & $\begin{array}{l}\text { Electroacoustics-Simulators of human head and ear-Part } 5: 2 \mathrm{~cm} 3 \text { coupler } \\
\text { for the measurement of hearing aids and earphones coupled to the ear by } \\
\text { means of ear inserts }\end{array}$ \\
\hline IEC 601261961 & $\begin{array}{l}\text { Reference coupler for the measurement of hearing aids using earphones } \\
\text { coupled to the ear by means of ear inserts (withdrawn) }\end{array}$ \\
\hline IEC 60318-4 2010 & $\begin{array}{l}\text { Electroacoustics-Simulators of human head and ear-Part 4: Occluded-ear } \\
\text { simulator for the measurement of earphones coupled to the ear by means of } \\
\text { ear inserts, Edition } 1.0\end{array}$ \\
\hline IEC 607111981 & Occluded ear simulator (withdrawn) \\
\hline IEC 609422003 & Electroacoustics—Sound calibrators \\
\hline IEC 61094-1 2000 & $\begin{array}{l}\text { Measurement microphones-Part 1: Specifications for laboratory } \\
\text { microphones }\end{array}$ \\
\hline IEC 616692001 & $\begin{array}{l}\text { Electroacoustics-Equipment for the measurement of real ear acoustical } \\
\text { characteristics of hearing aids (see also ISO 12124, 2001) }\end{array}$ \\
\hline ISO 121242001 & $\begin{array}{l}\text { Acoustics-Procedures for the measurement of real ear acoustical character- } \\
\text { istics of hearing aids (see also IEC } 61669,2001 \text { ) }\end{array}$ \\
\hline ISO 11904-1 2002 & $\begin{array}{l}\text { Acoustics-Determination of sound immission from sound sources placed } \\
\text { close to the ear. Part 1: Technique using microphones in real ears (MIRE } \\
\text { technique) }\end{array}$ \\
\hline ISO 11904-2 2004 & $\begin{array}{l}\text { Acoustics-Determination of sound immission from sound sources placed } \\
\text { close to the ear. Part 2: Technique using a manikin (manikin-technique) }\end{array}$ \\
\hline ISO 170252005 & $\begin{array}{l}\text { General requirements for the competence of testing and calibration } \\
\text { laboratories }\end{array}$ \\
\hline
\end{tabular}

Abbreviations: IEC, International Electrotechnical Commission; ISO, International Organization for Standardization; MIRE, microphone in real ear. 
Table 2 ANSI Standards Relevant to Hearing Aids and Hearing Aid Test Systems

\begin{tabular}{|c|c|}
\hline ANSI C63.19 2011 & $\begin{array}{l}\text { American National Standard Methods of Measurement of Compatibility } \\
\text { between Wireless Communications Devices and Hearing Aids }\end{array}$ \\
\hline $\begin{array}{l}\text { ANSI S1.15 Part } 1 \\
1997(R \text { 2011) }\end{array}$ & $\begin{array}{l}\text { American National Standard Measurement Microphones, Part 1: Specifica- } \\
\text { tions for Laboratory Microphones }\end{array}$ \\
\hline $\begin{array}{l}\text { ANSI S1.40 } 2006 \\
(R \text { 2001) }\end{array}$ & $\begin{array}{l}\text { American National Standard Specifications and Verification Procedures for } \\
\text { Sound Calibrators }\end{array}$ \\
\hline $\begin{array}{l}\text { ANSI S3.7 } 1995 \\
\text { (R 2008) }\end{array}$ & American National Standard Method for Coupler Calibration of Earphones \\
\hline ANSI S3.22 2014 & American National Standard Specification of Hearing Aid Characteristics \\
\hline ANSI S3.25 2009 & American National Standard for an Occluded Ear Simulator \\
\hline ANSI S3.35 2010 & $\begin{array}{l}\text { American National Standard Method for the Measurement of Performance } \\
\text { Characteristics of Hearing Aids under Simulated Real-Ear Working Conditions }\end{array}$ \\
\hline ANSI S3.36 2012 & $\begin{array}{l}\text { American National Specification for a Manikin for Simulated in situ Airborne } \\
\text { Acoustic Measurements }\end{array}$ \\
\hline $\begin{array}{l}\text { ANSI S3.37 } 1987 \\
(\text { R 2012) }\end{array}$ & $\begin{array}{l}\text { American National Standard Preferred Earhook Nozzle Thread for Postaur- } \\
\text { icular Hearing Aids }\end{array}$ \\
\hline $\begin{array}{l}\text { ANSI S3.42 Part } 1 \\
1992(R \text { 2012) }\end{array}$ & Testing Hearing Aids with a Broad-band Noise Signal \\
\hline ANSI S3.42 Part 2 & American National Standard Testing Hearing Aids_-Part 2: Methods for \\
\hline $\begin{array}{l}2012 / I E C ~ 60118-15 \\
2012\end{array}$ & $\begin{array}{l}\text { Characterizing Signal Processing in Hearing Aids with a Speech-like Signal } \\
\text { (nationally adopted international standard) }\end{array}$ \\
\hline ANSI S3.46 2013 & $\begin{array}{l}\text { American National Standard Methods of Real-Ear Performance Character- } \\
\text { istics of Hearing Aids }\end{array}$ \\
\hline ANSI S3.47 2014 & $\begin{array}{l}\text { Specification of Performance Measurement of Hearing Assistance Devices/ } \\
\text { Systems }\end{array}$ \\
\hline
\end{tabular}

Abbreviation: American National Standards Institute (ANSI).

although certain tests may be performed optionally with an ear simulator. Also, in a current update of S3.22 (2014), the annex containing the vertical magnetic field loop test was moved to the body of the standard, which, if adopted by the FDA, will make these tests required.

\section{TESTING WITH NOISE AND SPEECH SIGNALS}

- ANSI S3.42 part 1 (1992) and IEC 60118-2 (1996)

- ANSI S3.42 part 2 (2012) and IEC 6011815 (2012)

As stated above, the characterization of hearing aids in actual use can differ significantly from those determined in accordance with standards such as ANSI S3.22 (2014), IEC 60118-0 (1994), and IEC 60118-7 (2005). These stand- ards use non-speechlike test signals with the hearing aid set to specific test settings that are, in general, not comparable with typical user settings.

Rather than utilizing pure tones, as specified in ANSI S3.22 (2014), to determine the effect on frequency response of compression or other nonlinear processes, the original ANSI S3.42 part 1(1992) utilized a steady-state broadband noise input to determine hearing aid frequency response at different input levels. The resulting family of curves shown in Fig. 1 characterizes non-linear hearing aid signal processing better than a swept pure tone because the artifact known as blooming ${ }^{4}$ is eliminated. This general procedure was adopted later in an amendment of IEC 60118-2 (1996). However, using a steady-state broadband noise input does not demonstrate the effects on hearing aid processing of using a temporally varying signal such as speech. 


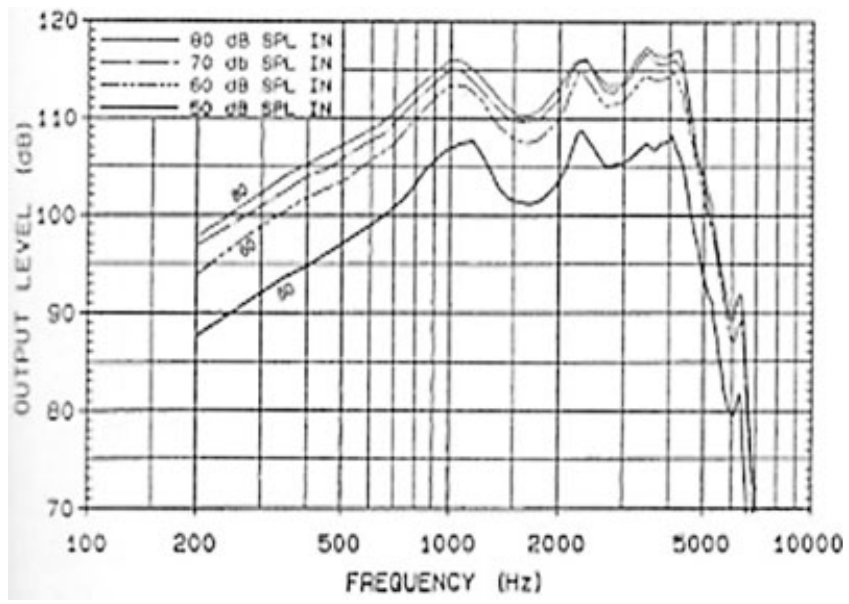

Figure 1 An example of a family of hearing aid frequency response curves (i.e., across input level). Reprinted from Preves Hearing Aids Standards and Options 1996, ${ }^{2}$ with permission of Thieme Medical Publishers.

For many years, the S3/WG48 committee on hearing aid measurements discussed an extension of the original ANSI standard S3.42 Part 1 (1992) that would utilize a temporally varying signal rather than the steadystate broadband noise input specified in $\mathrm{S} 3.42$ Part 1 (1992). Because the ANSI S3/WG48 committee could not achieve consensus on using one temporally varying signal, no ANSI standard resulted from this effort. However, in the meantime, the International Standards for Measuring Advanced Digital Hearing Aids (ISMADHA) group of the European Hearing Instrument Manufacturers Association $\left(\right.$ EHIMA $\left.^{5}\right)$ Technical Committee was drafting a hearing aid testing standard using the International Speech Test Signal (ISTS), which was designed to represent normal speech. ${ }^{6}$ The ISTS is based on the need for a complex, temporally varying test stimulus with speech properties that facilitates repeatable measurements. The ISTS comprises mixed, unintelligible recordings of speech segments from "The north wind and the sun" ${ }^{7}$ read by female speakers in six different languages (American English, Arabic, Chinese, French, German, and Spanish). The signal is based on the spectral changes in the long-term average speech signal that occur at different levels, and it describes hearing aid gain-frequency response at different percentiles of the speech level distribution. The EHIMA ISMADHA document later became IEC IEC60118-15 (2012) and was later adopted, at the recommendation of the S3/ WG48 committee, as is, to become ANSI S3.42 Part 2 (2012), an extension of S3.42 Part 1 (1992). IEC 60118-15 (2012) and ANSI S3.42 Part 2 (2012) are a good example of harmonization between IEC and ANSI hearing aid test standards because IEC 60118-15 (2012) filled the need for the desired extension of S3.42 Part 1 (1992) to use a temporally varying signal.

IEC 60118-15 (2012) and ANSI S3.42 Part 2 (2012) make frequency response measurements using the ISTS as a stimulus at different input levels with the hearing aid adjusted to actual use condition settings or to manufacturer-recommended settings for one of a range of audiograms (i.e., the hearing aid settings are programmed using the manufacturer's fitting software for one of the 10 standard audiograms included in the standard). The measured characteristics are comparable to those that may be obtained by a hearing aid wearer at typical use settings.

For the purposes of these standards, the hearing aid is considered to be a combination of the physical hearing aid and the fitting software that accompanies it. This procedure can demonstrate the performance characteristics of at least some adaptive-signal-processing features. The measurements are performed in an occluded ear simulator and are used to derive the estimated insertion gain. However, for the purpose of characterizing hearing aids during manufacturing, 
supply, and delivery, the standard also provides the procedures and requirements to derive the coupler gain on a $2-\mathrm{cm}^{3}$ coupler.

\section{TESTING HEARING AID-MOBILE PHONE ELECTROMAGNETIC COMPATIBILITY}

\section{- ANSI C63.19 (2011) and IEC 60118-13 (2011)}

The IEC 60118-13 (2011) and ANSI C63.19 (2011) standards specify electromagnetic compatibility (EMC) requirements of hearing aids. Originally, the main focus of these standards was to describe the amount of interference in hearing aid-processed audio that is caused by mobile phone handsets.

Experience in connection with the use of hearing aids in recent times has identified digital wireless devices (WDs) such as wireless telephones and global system for mobile (GSM) phones as potential sources of disturbance for hearing aids. Interference in hearing aids depends on the emitted power and the amount of modulation in the signal emitted by the digital WDs, as well as the immunity of the hearing aid. In practice, a hearing aid user, when using a wireless telephone, will seek, if possible, to find a position on the ear that gives the best coupling of the telephone signal with minimum noise interference in the hearing aid. WDs can cause two types of interference in hearing aids:

1. A buzzing from the modulation of the WD carrier frequency being demodulated by the hearing aid

2. A magnetically induced interference via the telecoil in hearing aids, caused by inductive energy at audio frequencies radiated by the display, keypad, and battery of the WD

ANSI C63.19 (2011) was developed in a subcommittee of Accredited Standards Committee C63, EMC, which is sponsored by the Institute of Electrical and Electronic Engineers. This standard assesses both radio frequency emissions and hearing aid immunity to interference, whereas IEC 60118-13 (2011) measures only hearing aid immunity. The methods de- scribed in these standards are not completely harmonized, but some attempts have been made to make their procedures similar if not identical; for example, although the primary method of testing hearing aid immunity in the C63.19 (2011) standard is via a dipole antenna, testing in the Gigahertz Transverse Electromagnetic, as specified in IEC 60118-13 (2011), is now included in the latest revision of the ANSI C63.19 (2011) as an alternate method. Recently, both standards have extended their measurement frequency ranges to account for new WDs that are coming into the marketplace. Hearing aid manufacturers have discovered through measurements for interference at higher frequencies that immunity to radio frequency interference decreases as WD carrier frequency increases. As Wi-Fi capability is included in cell phones using carrier frequencies near $2.45 \mathrm{GHz}$ and $5 \mathrm{GHz}$, no one knows for sure what the power level of these emissions will be or how hearing aids will react.

The performance criteria in the ANSI C63.19 (2011) and IEC 60118-13 (2011) standards do not ensure interference-free use of wireless telephones with hearing aids but do predict useable conditions in most situations. Various test methods have been considered for determining the immunity of hearing aids. In practice, based on studies of the maximum amount of interference that results in an acceptable signalto-interference ratio, the measured input-related interference level will be below 55-dB SPL when a bystander uses a mobile handset nearby (bystander condition) or when the hearing aid wearer uses a mobile handset (user condition).

Today most hearing aids contain digital signal processors and some contain wireless transceivers. These technology advancements have prompted a new revision of IEC 60118-13 (2011) that introduces additional specifications for EMC requirements for hearing aids. Hearing aids that have radio frequency transceivers for wireless communication require compliance to existing standards addressed by entities such as the Federal Communications Commission, radio and telecommunications terminal equipment, or other wireless directives. Hearing aids must meet radiated and immunity requirements to address general EMC compliance because they are medical devices. 
In addition, the current revision of IEC 60118-13 (2011) contains requirements for the amount of electrostatic discharge or electric shock that a hearing aid must be able to withstand.

\section{TESTING HEARING AID DIRECTIONALITY}

- ANSI S3.35 (2010) and IEC 60118-8 (2005)

The proliferation of directional hearing aids created the need for objective evaluation techniques to assess and compare their effectiveness. ANSI S3.35 (2010) and IEC 60118-8 (2005) were formulated for the measurement of the performance characteristics of hearing aids under simulated in situ working conditions using the Knowles electronic manikin for acoustic research (KEMAR) to test the simulated effect of the human head and torso on the performance of hearing aids. IEC 60118-8 (2005) also contains correction factor tables for converting free field to hearing aid microphone inlet SPL for different types of hearing aids, whereas ANSI S3.35 (2010) does not.

A round-robin experiment was performed in 2000 using the laboratory facilities of seven S3/WG48 members. Planar or horizontal twodimensional (2-D) polar pattern measures were made on a first-order directional behind-theear hearing aid, first in an anechoic chamber and then with it mounted on KEMAR. The resulting 2-D directivity index (DI) calculations were quite consistent across the seven laboratories: there was only a $0.7-\mathrm{dB}$ total range of 2-D DI, averaged across a frequency range of 200 to $6,300 \mathrm{~Hz}$, with the largest deviation across all laboratories being only $2.2 \mathrm{~dB}$ at $200 \mathrm{~Hz}$.

An earlier version of the ANSI S3.35 (2010) standard and the current version of IEC 60118-8 (2005) specified a 2-D directivity characterization, using a horizontal polar planar measurement obtained with the hearing aid mounted on a KEMAR manikin while the manikin is rotated. These 2-D directional measurements are only an approximation of actual three-dimensional (3-D) performance, because they assume vertical plane rotational polar pattern symmetry, which is usually not achieved with hearing aids mounted on KEMAR or a wearer. Because hearing aid wearers listen to sounds in a 3-D acoustical environment, the S3/WG48 committee felt that more accurate predictions of directional benefit achieved in actual use could be made with 3-D measurements. Consequently, the current version of ANSI S3.35 (2010) assesses the DI in three dimensions (in both the horizontal and vertical planes relative to KEMAR). Loudspeaker positions in ANSI S3.35 (2010) recommended for directional measurements in 2-D and 3-D are illustrated in the Fig. 2.

\section{MEASURING WIDEBAND HEARING AID PERFORMANCE}

- ANSI S3.25 (2009) and IEC 60318-4 (2006) versus IEC 60711 (1981)

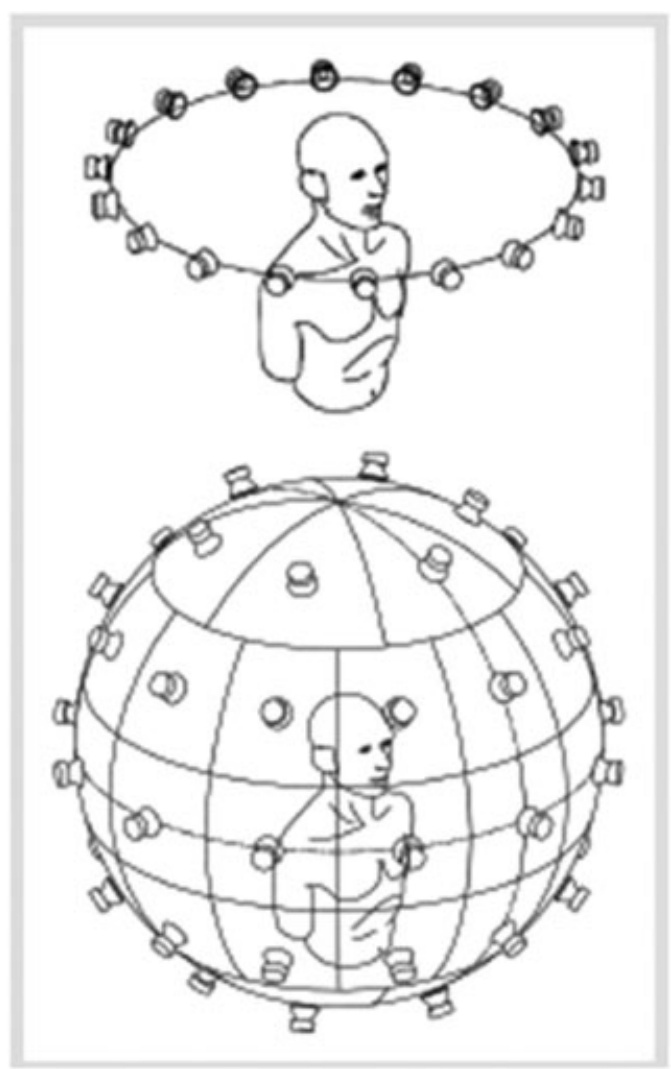

Figure 2 Illustration of recommended loudspeaker locations for two-dimensional (top) and three-dimensional (bottom) directional measurements. From Preves and Burns (2007), ${ }^{8}$ with permission of the Hearing Journal. 
The original values for transfer impedance in ANSI S3.25 (first version described only the modified Zwislocki ear simulator) and IEC 60711 (1981) were very similar. ANSI S3.25 (2009) values differed from those in IEC 60711 (1981) by less than $1 \mathrm{~dB}$ at a few frequencies. However, the modified Zwislocki ear simulator, made originally by Knowles Electronics, is no longer available and is no longer supported for repair. In a recent revision of IEC 60318-4 (2006), the transfer impedance tolerances were loosened and the frequency range was extended from the original 100 to $10 \mathrm{kHz}$ to 20 to $16 \mathrm{kHz}$. However, because of a lack of consistency caused by a sharp resonance in the IEC 60711 (1981) ear simulator between 12 and $14 \mathrm{kHz}$, doubts have arisen about whether ear simulators that comply with either the newer IEC 60318-4 (2006) or the IEC 60711 (1981) ear simulator are suitable for making representative and repeatable measurements on wideband hearing aids at frequencies above $10 \mathrm{kHz}$. This concern has led to the development of a $0.4-\mathrm{cm}^{3}$ coupler to make wide-band measurements.

- IEC draft technical specification (DTS) 62866 (draft of a future IEC standard)

Advancement in the hearing aid design makes it possible to increase the bandwidth of hearing aids up to $16 \mathrm{kHz}$. Accordingly, there is a need for an accurate and robust broadband measurement method that assesses high-frequency performance for the use by the transducer (receiver, ear phone) designer, the hearing aid designer, and fitter of hearing aids.

The $2-\mathrm{cm}^{3}$ coupler is suitable for measurements up to $8 \mathrm{kHz}$. The limitation is caused by unfavorable acoustic modes of the coupler. The ear simulator simulates the average external human ear up to $8 \mathrm{kHz}$ and can be used as a test coupler up to $16 \mathrm{kHz}$. A known issue is the very sharp one-half wavelength resonance at $\sim 12$ to $14 \mathrm{kHz}$, which degrades both the reproducibility of measurement results in that frequency range and the harmonic distortion measurements to the corresponding fraction of the resonance frequency. Also, this resonance exhibits a complex load to the hearing aid transducer, which makes it more difficult to differentiate between transducer- and loadrelated effects.

Due to these limitations, a new technical specification is under development. The effective internal volume of the coupler described in the new technical specification is $0.4 \mathrm{~cm}^{3}$, which is small enough so as not to produce any resonance in the frequency range below $16 \mathrm{kHz}$. Interestingly, Frye (Frye Electronics, Inc., Portland, OR) developed a $0.4-\mathrm{cm}^{3}$ coupler in 2005 to better determine the performance characteristics of deep-fitting hearing aids, but Frye states that it is not intended to be used at high frequencies. The impedance response of the $0.4-\mathrm{cm}^{3}$ coupler follows the pattern of a capacitive load up to $\sim 30 \mathrm{kHz}$. With sufficiently high-acoustic source impedance and sufficiently small coupling and volume, the $0.4-\mathrm{cm}^{3}$ coupler produces $\sim 14 \mathrm{~dB}$ higher output at $1 \mathrm{kHz}$ in comparison to data obtained with the $2-\mathrm{cm}^{3}$ coupler. The $0.4-\mathrm{cm}^{3}$ coupler described will allow characterizing hearing aids and transducers, including verification of simulation models of up to $16 \mathrm{kHz}$. In combination with an appropriate real ear probe microphone measurement discussed in the next section, the $0.4-\mathrm{cm}^{3}$ coupler will allow evaluation of real ear to coupler difference (RECD) up to $16 \mathrm{kHz}$.

Currently, the DTS 62866 document has been put forth as a technical specification, rather than an IEC standard, to allow sufficient time to gain experience using the $0.4-\mathrm{cm}^{3}$ coupler. There is some reservation in the ANSI S3/WG48 committee as to whether this approach is appropriate for high-frequency testing of high-impedance transducers. Instead, a terminated transmission line approach to an equivalent circuit might be closer to the performance of an unknown high-impedance sound generator. However, at the time of this writing, some of the few laboratories that have utilized the $0.4-\mathrm{cm}^{3}$ coupler have found that tests results appear to be stable and representative enough to raise the possibility that the $0.4-\mathrm{cm}^{3}$ coupler could someday replace the $2-\mathrm{cm}^{3} \mathrm{cou}-$ pler and the ear simulator specified in IEC 60318-4 (2010), formerly IEC 60711 (1981), even as a quality control coupler, while at the same time better characterizing the performance of current and future wide-bandwidth hearing aids. 


\section{MEASURING HEARING AID PERFORMANCE ON REAL EARS}

- ANSI S3.46 (2013) and IEC 61669 (2001)

These standards define terms that have been long used in practice to express real ear hearing aid performance. Included are real ear unaided response and real ear unaided gain, real ear occluded response and real ear occluded gain, real ear aided response (REAR) and real ear aided gain, and real ear insertion gain. The ANSI S3/WG80 committee recently updated ANSI S3.46 (2013) to include RECD, real ear aided response 85 or 90 (REAR85 or REAR90), which has been expressed previously as real ear saturation response, and the real ear to dial difference. Use of the ISTS for real ear testing was also added in this revision of ANSI S3.46 (2013). The corresponding IEC real ear WG also updated IEC 61669 (2001) to be harmonized with ANSI S3.46 (2013).

Members of the ANSI S3/WG80 committee that formulated the ANSI S3.46 (2013) standard found that inclusion of the RECD measurement in an ANSI S3.46 (2013) update was somewhat difficult because of widely varying methods of performing this measurement and uses of the term RECD, especially in clinical settings in which the HA-2 coupler configuration and different tubing may be used for the coupler and real ear parts of the measurement. The inconsistent use of different tubing for the coupler and real ear parts of the RECD calculation was not what was originally intended for the RECD. There also was concern that high acoustic output impedance sources (e.g., insert earphones like the Etymotic Research ER-3A (Etymotic Research, Inc., Elk Grove Village, IL) having a higher acoustic impedance than hearing aid receivers) are sometimes used to measure the RECD on infants, which would produce results not representative of the actual RECD obtained with a hearing aid. Because of these and other varying practices in the field, RECD measurements for a specific hearing aid and wearer could be quite variable across facilities. Clauses in the 2013 revision of ANSI S3.46 (2013) were added to discourage these practices by pointing out common pitfalls and to narrow the definition of RECD. The ANSI S3.46 (2013) revision has several explanatory notes included in the definition of RECD and an extensive Annex $\mathrm{C}$ that document potential sources of errors in performing RECD measurements. For the RECD calculation, ANSI S3.46 (2013) essentially recommends that the coupler (the HA-1 coupling configuration) utilize the actual tubing and earmold (or eartip) that is used for the real ear part of the measurement, and the same high-impedance sound source for both the coupler and real ear measurements.

\section{TESTING ASSISTIVE LISTENING DEVICES OR HEARING ASSISTIVE DEVICES INCLUDING WIRELESS HEARING AID SYSTEMS}

\section{- ANSI S3.47 (2014)}

This standard describes definitions and measurements for the specification and evaluation of hearing assistance devices/systems (HADS), devices with varying physical configurations that amplify an acoustic signal and/or improve the signal-to-noise ratio using in part non-acoustic signal transmission. Examples of HADS include personal assistive listening devices, hearing assistance technologies, auditory trainers, large-area assistive listening systems, telephone amplifiers, and alerting devices, but this standard address only devices that transmit directly to a person via earphones or hearing aid. HADS are classified into one or more of the following categories of transmission methods: hardwired or wireless, which includes radio frequency or near-field induction, audio frequency induction, and infrared. Hearing aid delivery includes direct electrical input, via an induction coupling through the telecoil of the hearing aid or via a built-in receiver such as a frequency-modulation (FM) transceiver in the hearing aid. The scope of ANSI S3.47 (2014) is limited to performance measurement of devices not worn entirely on the body. For example, one application of the standard would be measuring the input-output characteristics of a remote microphone system (e.g., an FM transmitter on a teacher transmitting the teacher's voice to an FM receiver connected to a neckloop that relays a corresponding magnetic signal to a telecoil in a hearing aid worn by a person). 
Some hearing aids incorporate both amplifiers and wireless transceivers. ANSI S3.47 (2014) recommends that the amplification via the internal hearing aid microphone be tested by ANSI S3.22 (2014) and the wireless communication functionality with remote audio devices be tested according to ANSI S3.47 (2014). Because the overall functionality of HADS and hearing aids are similar, many of the tests in ANSI S3.47 (2014) were adopted from ANSI S3.22 (2014) and applied with any test setup variations required for HADS testing. Early on, during the many years that were required for the development of this standard, the ANSI S3/WG81 committee members who formulated ANSI S3.47 (2014) needed to create definitions that clearly distinguished the differences between hearing aids and HADS. Interestingly, the result was a consensus definition for a hearing aid that was subsequently included, for the first time, in a recent revision of ANSI S3.22
(2014), after ANSI S3.22 had been in use for nearly 40 years!

\section{EXAMPLES OF AVAILABLE HEARING AID PERFORMANCE ANALYSIS SYSTEMS}

In this section, examples of both dedicated hearing aid analyzers and general purpose test equipment are presented. Some of the measurements these test instruments can be set up to perform are taken from ANSI S3.22 (2014), ANSI S3.46 (2013), and IEC 60118-0 (1994), IEC 60118-7 (2005), IEC 60118-15 (2012), and IEC 61669 (2001) include:

- Gain and output:

- Output SPL response, full-on acoustic gain, frequency response, and effects on gain and output SPL 90 with different battery impedance or voltage settings

- Amplitude nonlinearities:

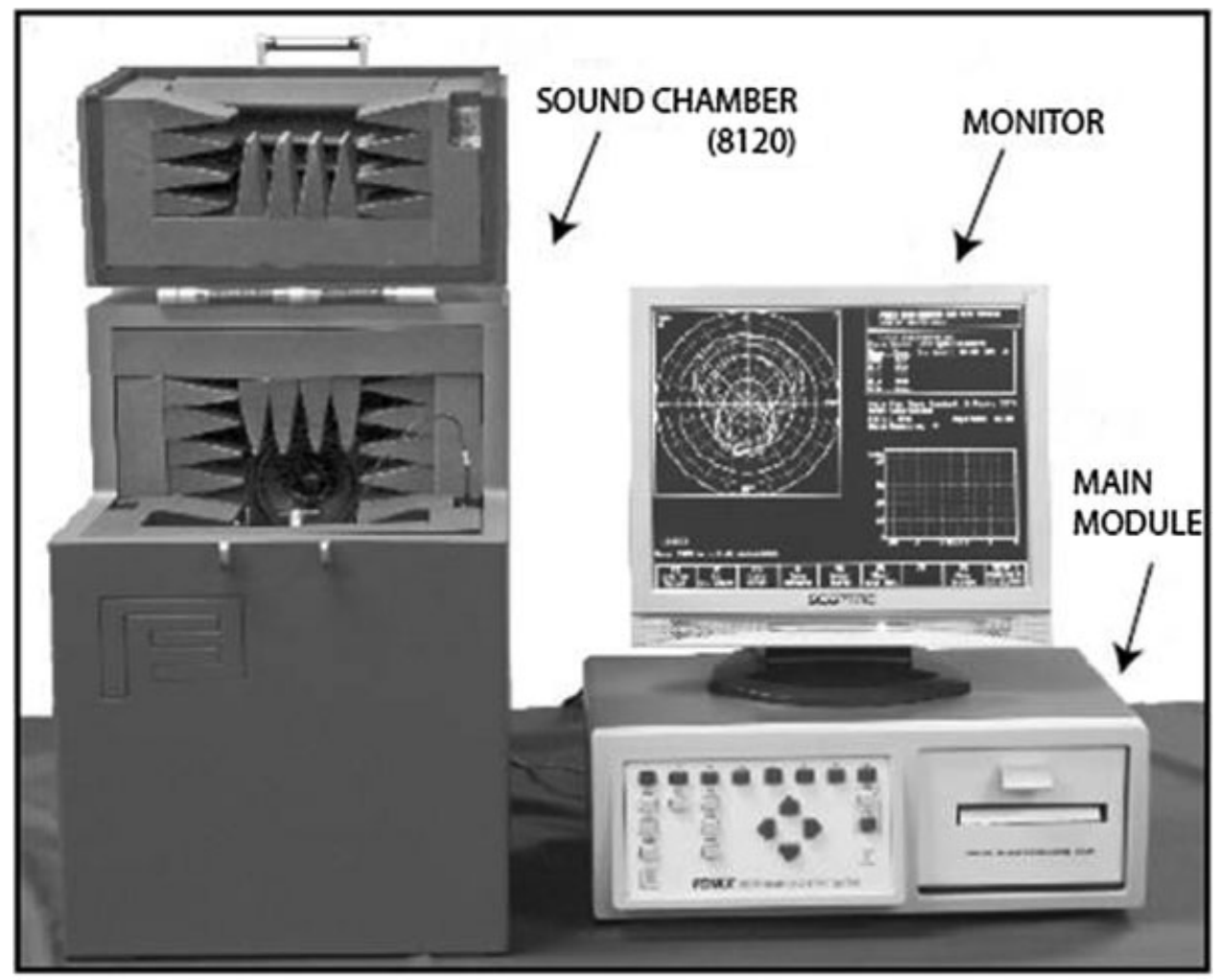

Figure 1.6.1.-The 8000 Test system.

Figure 3 The Frye 8000 Test System. Reprinted with the permission of Frye Electronics (Frye Electronics, Inc., Portland, OR). 
- Harmonic distortion and intermodulation distortion

- Internal noise generation

- Battery current

- Induction pickup coil performance:

- Frequency response and harmonic distortion

- Automatic gain control:

- Input/output characteristics for sinusoidal signals, and dynamic output for different speech signals at different levels

- Real ear performance

\section{CLINICAL INSTRUMENTS}

- Frye Fonix 8000 and FP35 Touch hearing aid analyzers

The Frye 8000 test system (see Fig. 3) comes with a Frye 8050 or 8120 sound chamber. Both the 8000 and FP35 Touch analyzers can use the same microphones and couplers, although Frye makes its own 14-mm diameter precision microphone for use with the 8000 analyzer. Frye states that the 8000 utilizes a leveling system rather than a feedback microphone to equalize the sound chamber to reduce test time and to prevent acoustic feedback emanating from open-fit hearing aids from affecting their measurement.

\section{- Etymonic Design-Audioscan Verifit}

Historically, Audioscan has focused on incorporating real ear measurement capability in its hearing aid analyzers, in accordance with ANSI S3.46, and their testing features have often lead the way for updates to that standard. Audioscan has pioneered several testing fea- tures in its Verifit line of dedicated hearing aid analyzers. Among these are Speechmapping, with which the hearing aid output in the ear canal is measured with real speech and compared on the same graph to an individual's hearing loss and loudness discomfort level.

The recently introduced Verifit2 (see Fig. 4) utilizes a binaural test box that provides capability for confirming the latest hearing aid features, including wireless communication between paired hearing aids (e.g., synchronized volume control and programming adjustments for binaural hearing aid fittings and verification of wireless streaming functionality in hearing aids). For these tests, the two hearing aids are mounted vertically facing the main speaker (see Fig. 4). The Verifit2 (Audioscan Verifit $2^{\circledR}$, Dorchester, Ontario, Canada) also performs frequency response measurements to $16 \mathrm{kHz}$ and has tests for verifying adaptive directionality, noise reduction, frequency lowering, and feedback suppression. The Audioscan Verifit website $^{9}$ contains interesting and valuable specifications, videos, a product comparison chart of Audioscan hardware and software features, and hints called "verification myths" that debunk several popularly held beliefs about hearing aids.

\section{LABORATORY INSTRUMENTS}

Many laboratory instruments are used for hearing aid research and development and/or hearing aid production test environments. These devices are briefly described below. The dedicated hearing aid testers cited above for clinical use can perform tests taken from ANSI S3.22 (2014), IEC 60118-7 (2005), and IEC 6011815 (2012). Many of the laboratory test systems

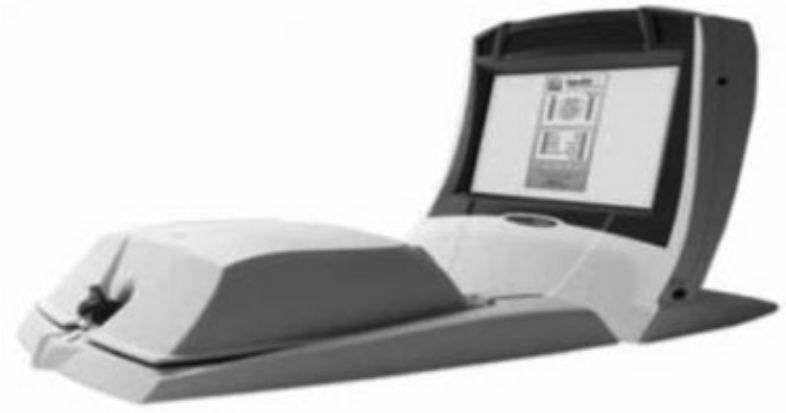

Figure 4 Audioscan Verifit2. Reprinted with permission of Audioscan (Audioscan Verifit2 ${ }^{\circledR}$, Dorchester, Ontario, Canada). 


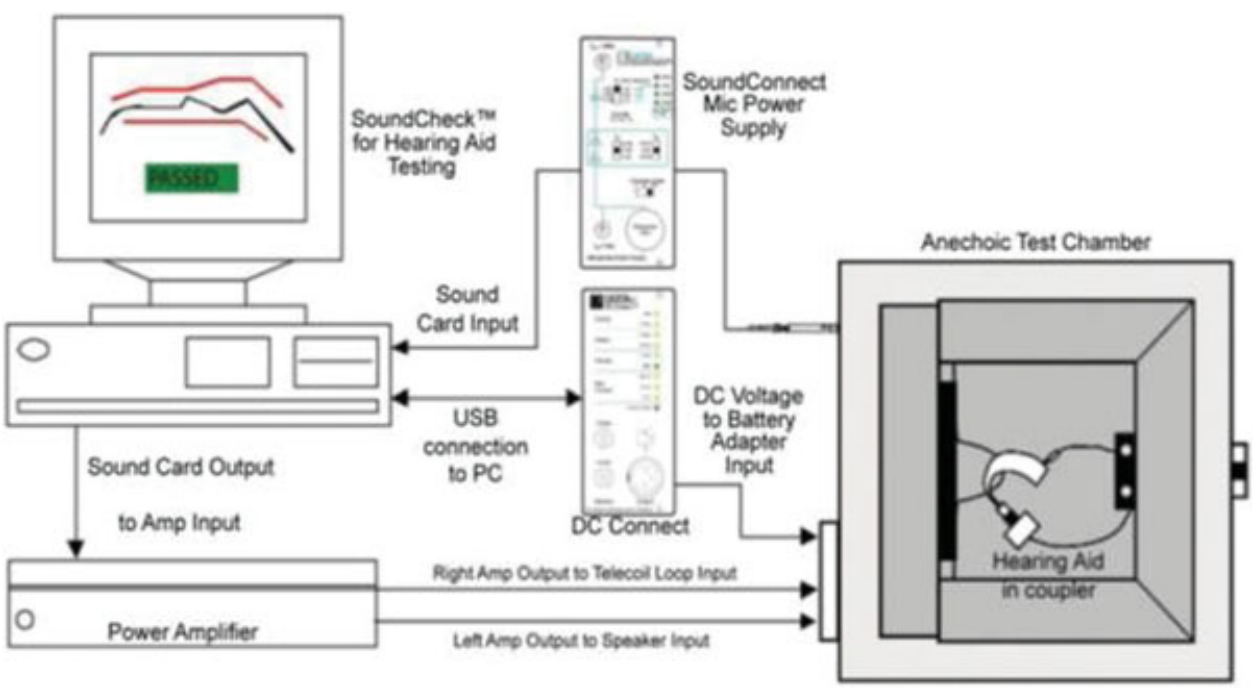

Figure 5 The Listen Soundcheck. Reprinted with permission of Listen, Inc. (Listen, Inc., Boston, MA).

(as well as some of the dedicated clinical hearing aid testers) can perform additional measurements and functions beyond those recommended in ANSI and IEC hearing aid performance test standards including, for example:

- Peak gain and frequency of peak gain determination

- Phase and group delay

- Subcomponent tests
- Data recording of sound and logging of test scenarios for use in further testing and analysis

- Feedback check with no generator on indicates whether feedback is present

- Listen SoundCheck (Listen, Inc., Boston, MA).

SoundCheck ${ }^{10}$ is an audio test and measurement system that is used for general audio industry applications (see Fig. 5). The system

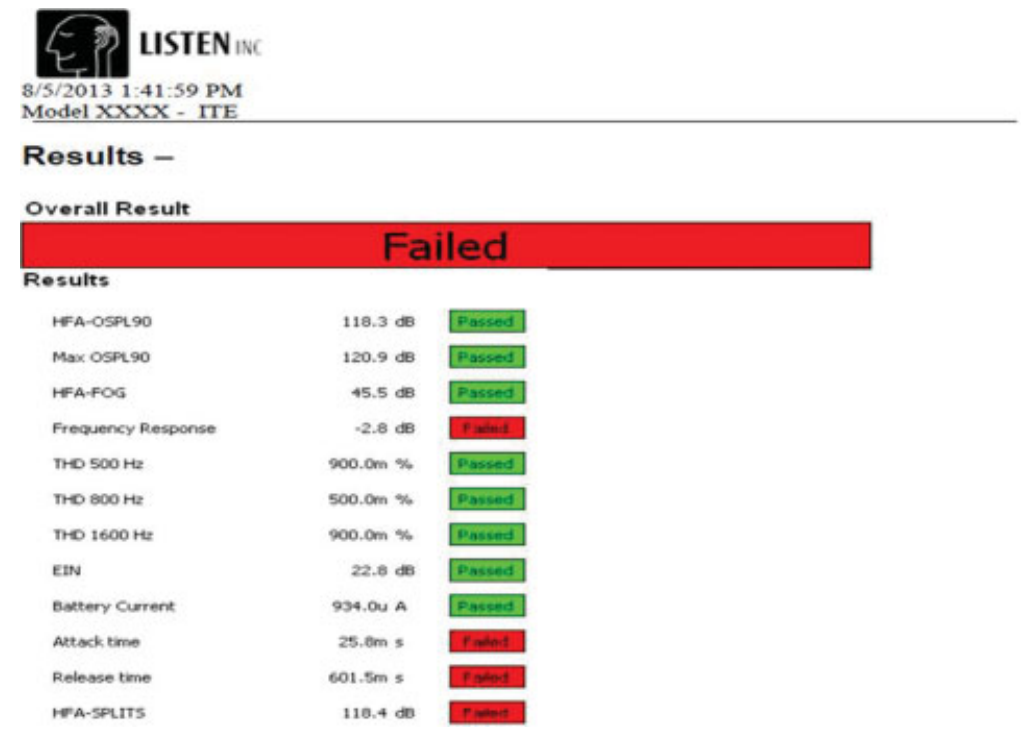

Figure 6 Results screen for hearing aid measurements performed on the Listen Soundcheck. Reprinted with permission of Listen, Inc. (Listen, Inc., Boston, MA). 
can be configured to run a large variety of measurements, including standard metrics like frequency response, gain, and distortion, as well as nontraditional measurements such as perceptual distortion.

The Listen SoundCheck ${ }^{10}$ offers a set of prewritten test scripts for performing measurements in accordance with the ANSI S3.22 (2014) and IEC 60118-7 (2005) standards (see Fig. 6). This sequence package is available as an add-on to a standard SoundCheck license, and, with the appropriate hardware, allows all the tests from these two standards to be run, including some of the optional tests in the annexes of ANSI S3.22. Each of these sequences may be run independently and utilize the tolerances created in a Limits Entry sequence. A sequence editor allows the creation of userdefined test scripts.

The test chamber, microphones, couplers and telecoil test fixtures used with the SoundCheck system can be provided from Interacoustics (Interacoustics A/S, Denmark), Brüel \&
Kjær (B\&K) (Brüel \& Kjær Sound and Vibration Measurement A/S, Denmark), G.R.A.S. (G.R.A.S. Sound \& Vibration A/S, Denmark), and Frye (Frye Electronics, Inc., Portland, OR), via Listen (Listen, Inc., Boston, MA), or may be supplied by the user. Listen also has been involved in formulating and implementing objective tests that correlate to human listening perception, including noncoherent distortion and the SoundCheck Cepstral Loudness Enhanced Algorithm for Rub \& Buzz (CLEAR) Perceptual Rub \& Buzz algorithm.

- Rohde \& Schwarz (R\&S) UPV Audio Analyzer (Rohde \& Schwarz, Columbia, MD)

$R \& S^{11}$ has several options for hearing aid measurements comprising generalized hardware used with specific hearing aid-related software programs. R\&S UPV (see Fig. 7) is a self-contained audio analyzer that tests per ANSI S3.22 and IEC 60118-0 (1994), 60118-1 (1999), 60118-2 1996), and 60118-7 (2005)
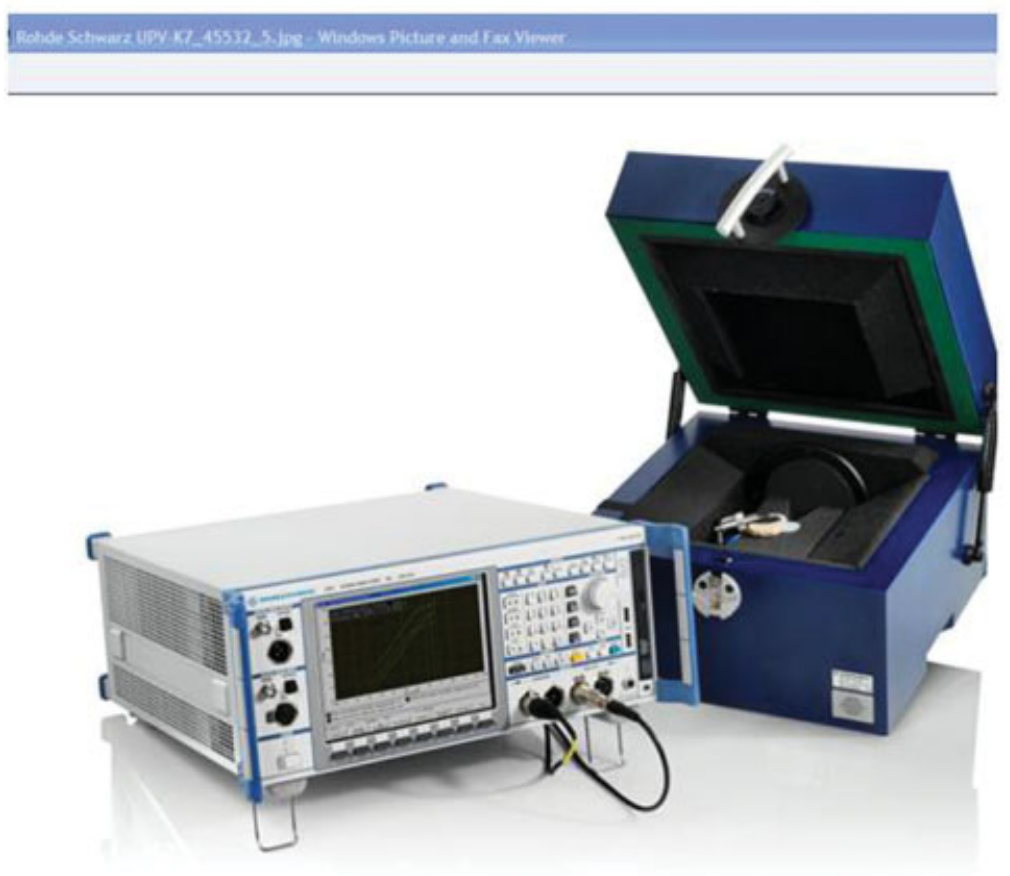

Figure 7 Rohde \& Schwarz UPV-K7 system. Reprinted with permission of Rohde \& Schwarz (Rohde \& Schwarz, Columbia, MD). 
using the R\&S UPV-K7 software package. Customized test routines such as user-defined test sequences with single- and multifrequency sine wave signals and a variety of noise test signals can be created. Measurements per IEC 60118-15 (2012) can be performed with the R\&S UPV-K71 software extension option. Like several other general purpose audio analyzers, R\&S uses the Interacoustics TBS25 test box. Calibration data are stored in a database.

- Audio Precision (AP) (Audio Precision, Beaverton, OR) APx511

AP ships the $\mathrm{APx} 511^{12}$ (see Fig. 8), which is intended for production testing of hearing aids, with a Certificate of Calibration and individual Calibration Report that is traceable to the National Institute of Standards and Technology. The APx511 Hearing instrument analyzer supports continuous sweep (i.e., a chirp or glide) and multitone test techniques. Test sequences may be customized by modifying the hearing instrument dynamic link library software, which runs on a personal computer and comes with automated routines for all ANSI S3.22 (2014) and IEC 60118-7 (2005) measurements . Typical test time is 2 minutes using an 80 -frequency multitone and 2.5 to 3 minutes using singlefrequency swept measurements. Like several other general purpose audio analyzers, AP uses the Interacoustics TBS25 test box. The AP Calibration Laboratory is accredited by A2LA to the International Organization for Standardization (ISO) 17025 (2005) standard.

AP provides calibration data sheets with its half-inch and 14-mm diameter pressure microphones, which are designed to be interchangeable with GRAS and B\&K half-inch microphones and Frye microphones, respectively. HA-2 and HA-2 type $2-\mathrm{cm}^{3}$ coupling configurations are available that conform to the ANSI S3.7 (1995) and IEC 60126 (1961) (now IEC 60318-5 1983) coupler standards.

\section{- B\&K PULSE analyzer}

Hearing aid measurements may be performed with $\mathrm{B} \& \mathrm{~K}^{13}$ microphones, preamplifiers, and couplers in the B\&K 4232 test chamber (Interacoustics TBS25 chamber). Additionally, B\&K has ear, head, torso, and mouth simulators to make hearing aid-related measurements other than quality control. B\&K has developed a robot-controlled, near-field acoustic holography system called SONAH for identifying feedback and its source(s), due to acoustic leakage or vibration in hearing aids. In this system, a robot moves a probe microphone systematically and repeatably on a predefined track to map the sound field near a hearing aid

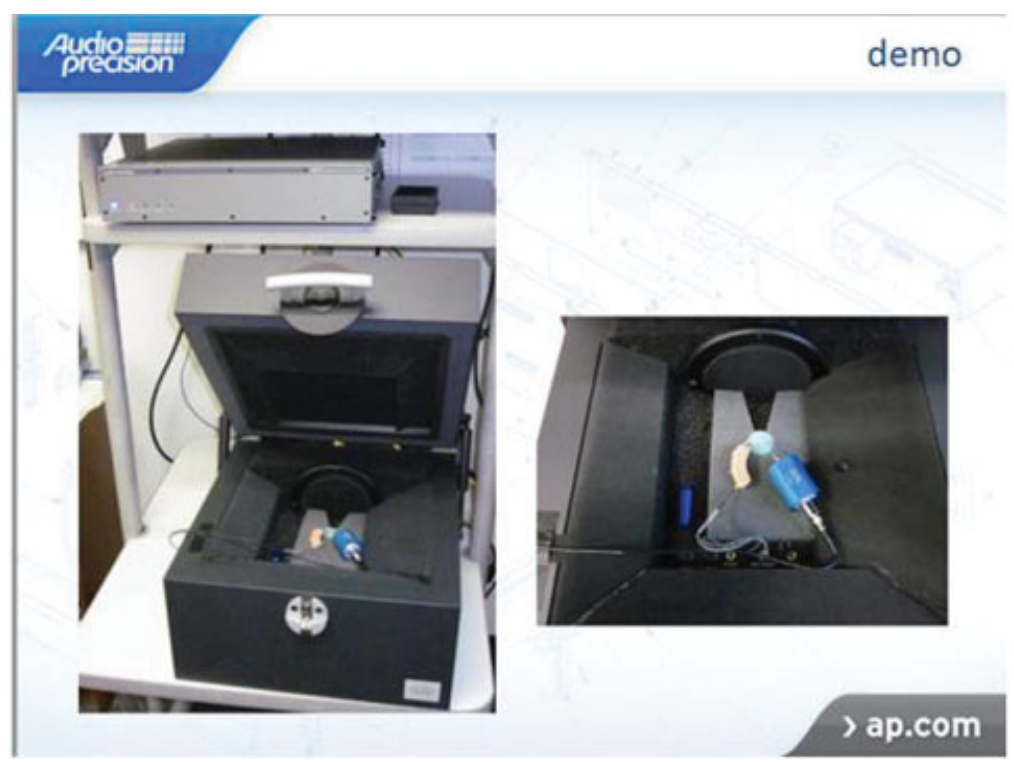

Figure 8 The APx511. Reprinted with permission of Audio Precision (Audio Precision, Beaverton, OR). 
in small steps. The conformal sound maps resulting may be obtained in situ while a hearing aid is worn. When combined with computer models of a hearing aid, they can show via different colors "hot spots," which indicate relative sound intensity differences at specific locations near the hearing aid. ${ }^{14}$

- G.R.A.S.

G.R.A.S. ${ }^{15}$ provides laboratory microphones, calibrators, couplers, ear simulators, and head and torso simulators, including manikins, for hearing aid testing.

\section{CALIBRATION OF HEARING AID PERFORIMANCE ANALYZERS}

Calibration of the hearing aid test equipment is needed to ensure that the measurements are correct to build confidence in the measurements and to ensure product quality. The steps of calibrating include:

- Proving that measurement methods and the equipment used are accurate, for example, to prove that a measurement complies with the requirements of national legislation, standard bodies, and customers

- Verifying the stability of the measurement equipment, including equipment used to perform calibration

- Accounting for local measurement conditions (e.g., variations in ambient pressure and temperature)

Several clauses in the ANSI S3.22 (2014) and IEC 60118-7 (2005) quality control-related standards specify acceptable tolerances for test equipment accuracy. These tolerances define test limits for calibration parameters needed for hearing aid performance analyzers to meet the test equipment requirements in these standards. The following are included (as excerpted from ANSI S3.22 2014).

\section{Sound Source and Test Signal}

The sound source shall be able to deliver SPLs between 50 and $90 \mathrm{~dB}$ at the sound entrance on the hearing aid. Using a calibrated control microphone system or other means, the SPL at the sound entrance shall be maintained within $\pm 1.5 \mathrm{~dB}$ from 0.2 to $2.0 \mathrm{kHz}$ and within $\pm 2.5 \mathrm{~dB}$ from 2.0 to $5.0 \mathrm{kHz}$. This can be verified by comparison to readings made with a type 1 sound level meter or a microphone and associated measurement system. For frequency response and harmonic distortion measurements, the total harmonic distortion of the acoustic test signal shall not exceed 2 and $0.5 \%$, respectively. The frequency of the test signal shall be accurate to within $\pm 2 \%$.

\section{Microphone Used in Coupler}

The pressure frequency response of the microphone used in the earphone coupler, including its amplifier and display, shall be uniform within $\pm 1 \mathrm{~dB}$ over the frequency range 0.2 to $5.0 \mathrm{kHz}$. The calibration of the microphone system shall be accurate at frequencies between 0.25 to $1.0 \mathrm{kHz}$ to within $\pm 1 \mathrm{~dB}$.

\section{Test Space}

The test signal shall exceed the ambient noise at every analysis frequency (or in every analysis band) by at least $10 \mathrm{~dB}$. Unwanted stimuli in the test space, such as ambient noise or stray electrical or magnetic fields, shall be sufficiently low so as not to affect the test results by more than $0.5 \mathrm{~dB}$.

\section{Current Measurement}

The device used to measure current drain shall have an accuracy of $\pm 5 \%$ or better.

Sensitivity of the hearing aid tester microphone(s) is one of the most important parameters to calibrate and is defined as the ratio of an output parameter to the associated input parameter. Determining the sensitivity of the microphones used in a hearing aid tester is one of the first steps in calibrating the measurement device.

Frye provides an extensive set of calibration and maintenance manuals for the 8000 and FP35 Touch hearing aid analyzers in their excellent online library at Frye.com/wp/manuals. ${ }^{16}$ Detailed procedures are provided for user calibration of the test system, reference microphones, coupler microphones, and probe 
microphones with a sound calibrator. The Frye 8000 hearing aid analyzer has few external calibration adjustments, because most are internal to the analyzer. They suggest that system and microphone calibration for the FP35 hearing aid analyzer be done once a year at a minimum and more often if necessary. Frye recommends that calibration be done after the FP35 system has stabilized to room temperature (temperature is displayed on the FP35 Calibration Screen). Caution is recommended when checking FP35 microphone calibration, because the microphone calibration data are stored in the microphone connector rather than in the FP35 analyzer.

Checking microphone calibration is done with an acoustic calibrator or pistonphone, which produces a sound output within tight tolerance at a particular SPL and frequency. Examples of portable, battery-operated acoustic calibration devices include the following.

\section{B\&K 4231 Calibrator}

A pocket-size device that provides a $1,000-\mathrm{Hz}$ tone of $94 \pm 0.2 \mathrm{~dB}$ re: $20 \mathrm{~Pa}$ per IEC 942 Class 1. The $+20-\mathrm{dB}$ level step gives $114-\mathrm{dB} \mathrm{SPL}$, which is convenient for calibration in noisy environments. The sound pressure produced is independent of the microphone equivalent volume.

\section{M Quest QC-10 and QC-20 Sound Calibrators (Quest Technologies (a 3M company), Oconomowoc, WI)}

- QC-10: 1,000-Hz tone at 114-dB SPL

- QC-10: 250 and 1,000 Hz, each at 94- and 114-dB SPL, recommended for use with ANSI and IEC type 1 sound-level meters

Both devices meet ANSI S1.40 (2006) and IEC 60942 (2003) Class 1 standards.

If even greater accuracy is desired, a pistonphone rather than an acoustic calibrator may be used as per the following examples:

\section{G.R.A.S. 42AP Pistonphone}

This pistonphone provides a $250-\mathrm{Hz}$ or $251.2-$ $\mathrm{Hz}$ tone $\pm 0.1 \%$ at $114 \pm 0.05 \mathrm{~dB}$ re: $20 \mathrm{~Pa}$, independent of atmospheric pressure and altitude utilizing built-in barometer and thermometer. It can be controlled remotely via an RS-232 interface, and is delivered with a calibration chart.

\section{B\&K 4228 Pistonphone}

At reference conditions, this pistonphone provides a $250-\mathrm{Hz}$ tone (actually $251.2 \mathrm{~Hz}$ $\pm 0.1 \%$, as defined by ISO 266) at $124 \pm 0.2$ $\mathrm{dB}$ re: $20 \mathrm{~Pa}$ for calibration of sound-measuring equipment, including sound level meters, per IEC60942 (2003) Class 1L and with an external barometer satisfies IEC 60942 (2003) Class OL and ANSI S1.40 (2006). It is individually calibrated to within $\pm 0.12 \mathrm{~dB}$ including the effects of specified microphones and is delivered with a calibration chart.

\section{G.R.A.S. 90CA Microphone Calibration System}

This calibration system provides automated level and frequency response calibration of IEC 61094-1 (2000) standardized measurement microphones conforming to ANSI 1.15 part 1 (1997) and IEC 60318-1 and -2 standards. A typical calibration certificate is shown in Fig. 9.

Listen provides detailed calibration information in their Hearing Aid Standard Sequences note, ${ }^{17}$ including step-by-step instructions for calibrating the coupler/reference microphone, anechoic box sound source and TMFS (Frye Telewand) and loop (B\&K 4232 sound box loop) test fixtures for telecoil tests.

\section{HOW TO DO THE CALIBRATION}

Generally, the following steps are followed when calibrating sensitivity for a system that has both a reference microphone and a measurement microphone:

- The reference, coupler, and ear simulator microphones are calibrated by measuring their sensitivity via a certified acoustic calibrator or pistonphone.

- The reference microphone is placed at the measurement position in a test chamber. 


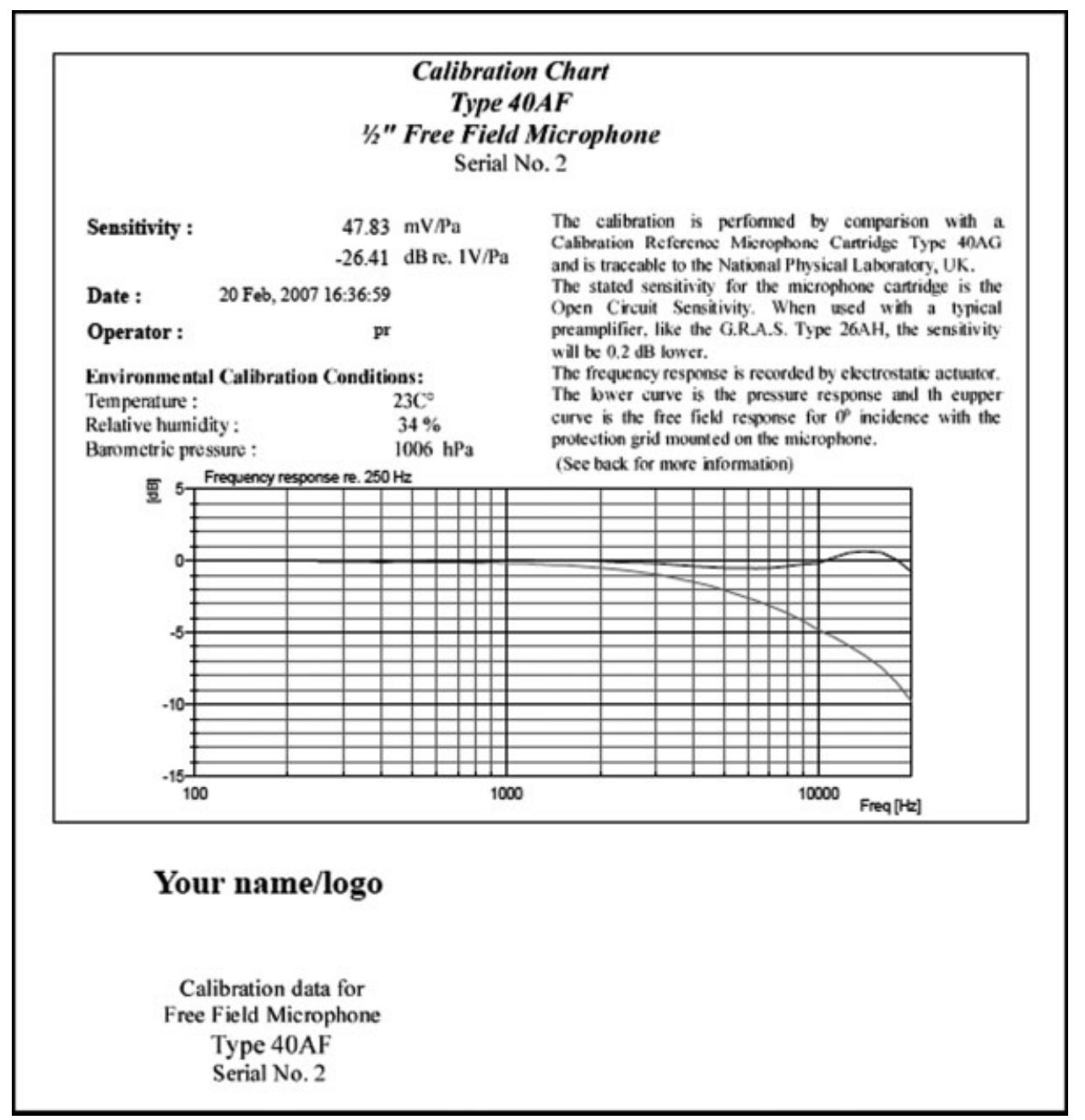

Figure 9 A typical calibration chart for a G.R.A.S. microphone. Reprint with permission of G.R.A.S. (G.R.A.S. Sound \& Vibration A/S, Denmark).

The speaker in the chamber is then calibrated by driving a sine sweep through the speaker and measuring its response via the reference microphone. This response is inverted and applied as an equalization for all of the measurements that follow.

Some hearing aid analyzers do not use a reference microphone to level or equalize the sound input to hearing aids, but $\backslash$ instead determine and store the equalization values for use later. This procedure is called the equivalent substitution method, as specified in Annex A of ANSI S3.22 (2014). For example, as mentioned previously, the Frye 8000 employs the equivalent substitution method of equalizing the test chamber as follows: the measurement or coupler microphone is placed at the reference point in the chamber and then, during the leveling process, the deviation of sensitivity of the acoustic source from the desired level is analyzed over frequency. A finite impulse response filter is then generated to correct these response irregularities. Any signal that is then sent to the sound chamber, including the ISTS and white or pink noise signals, is passed through this real time filter to remove system level deviations to within $1 \mathrm{~dB}$. 
The extensive Audioscan Verifit User's Guide provides detailed calibration procedures in http://www.audioscan.com/Docs/RM500 SLmanual.pdf.

\section{LIMITATIONS, ISSUES, AND PROBLEMS WITH CURRENT STANDARDS}

Although some of the hearing aid analyzers discussed have their own methods of assessing some of the more recent adaptive features incorporated in hearing aids, there are no standard methods to evaluate the performance of such features as adaptive directionality, adaptive noise management, feedback cancellation, and frequency transposition.

For example, ANSI S3.35 (2010) specifies how to measure and calculate a 3-D directional index on KEMAR. However, currently the standard states that earmold vents are to be occluded and adaptive features are to be disabled for these directional measures. Members of the ANSI S3/WG48 committee on hearing aid measurements recognize that a closed vent condition is not representative of real world use, and, in part, because of the recent popularity of open fit hearing aids, the standards committee has been investigating how large vents may affect directionality measures. It was found that the signal path for open fit hearing aids can be broken down into a direct-acousticthrough-the-vent contribution and an amplified contribution. Depending on their relative amplitudes and phases, the sum of these two signal paths often produces a comb-ripple effect in both frequency response and DI, with the direct portion degrading the 3-D simulated real ear DI by up to $3 \mathrm{~dB} .^{18}$

Standardizing methods for feedback cancellation is another area that also is receiving attention currently within a subgroup of the ANSI S3/WG48 committee. The subgroup has been considering how to set up hearing aids physically, how an acoustic feedback condition is created, and both objective and subjective measurement metrics of gain before onset of feedback oscillation and sound quality using some type of tonal signals, respectively. This is proving to be a daunting standardization challenge, but a worthwhile one.

\section{CONCLUSION}

Concerted efforts toward harmonization are being made currently by hearing aid-related ANSI and IEC standards committees. Members of these standards committees devote many voluntary hours to standardization efforts. There is much challenging work remaining to be done before standards can be formulated for adaptive features incorporated in currently marketed hearing aids. Because standards represent consensus opinions and practices, generating and publishing a new standard or updating an existing standard requires considerable time. Because of that, standards to evaluate features introduced in current hearing aids will always lag behind their proliferation, and will always be trying to catch up with existing technology. Those utilizing and having an interest in products that can be assessed by the standards discussed in this article should consider participating in the standards development process.

\section{REFERENCES}

1. Lybarger SF, Preves DA, Olsen WO. A bit of history on standards for acoustical measurements of hearing aids. Am J Audiol 1999;8(1):3-5

2. Preves D. Standardizing hearing aid measurement parameters and electroacoustic performance tests. In: Valente M, ed. Hearing Aids: Standards, Options, and Limitations. New York, NY: Thieme; 1996

3. Knowles. Zwislocki Coupler Evaluation with Insert Earphones. Sachs R, Burkhard M. Report 20022-1. Knowles Electronics 1972

4. Preves DA, Beck LB, Burnett ED, Teder H. Input stimuli for obtaining frequency responses of automatic gain control hearing aids. J Speech Hear Res 1989;32(1):189-194

5. European Hearing Instrument Manufacturers Association (EHIMA). Testing hearing aids with a speech-like signal. European Hearing Instrument Manufacturers Association; 2006

6. Holube I, Fredelake S, Vlaming M, Kollmeier B. Development and analysis of an International Speech Test Signal (ISTS). Int J Audiol 2010; 49(12):891-903

7. Wikipedia. The North Wind and the Sun. Available at: http://en.wikipedia.org/wiki/The_North_Wind_ and_the_Sun. Accessed on December 18, 2014 
8. Preves D, Burns T. Revised ANSI standard measures hearing aid directionality in 3D. Hear J 2007; 60(1):45-49

9. Audioscan. Verifit. Available at: http://www.audioscan.com/Verifit/. Accessed on December 18, 2014

10. Listen. New CLEARTM Perceptual Rub \& Buzz Algorithm Listens like a Human. Available at: http://www.listeninc.com/us/news_events/ PR_10_07_CLEAR_perceptual_rub_buzz.html. Accessed on December 18, 2014

11. Rohde \& Scharz. Common Library Search. Available at: http://www.rohde-schwarz.com/en/search/ common-library_63448.html?facet=facet.Com monLibraryType\&facet.CommonLibraryType= Manuals\&term=UPV. Accessed on December 18, 2014

12. Audio Precision. Available at: http://ap.com. Accessed on December 18, 2014
13. Bruel and Kjaer. Available at: http://www.bksv. com. Accessed on December 18, 2014

14. Dirks G, Gade S, Hald J. The use of near field acoustic holography for lek detection in miniature objects, such as hearing aids. Denmark: Bruel \& Kjaer; 2005

15. G.R.A.S. Sound \& Vibration. Available at: http:// www.gras.dk. Accessed on December 18, 2014

16. Frye Electronics. Manuals. Available at: http:// www.frye.com/wp/manuals/. Accessed on December 18, 2014

17. Listen Inc Sequence Note-Hearing Aid Standard Sequences P/N 3000. Available at: www.listeninc. com. Accessed on December 18, 2014

18. Burns E, Preves D. Computing the in situ Directivity Index of open-fit hearing aids. Paper presented at the American Auditory Society meeting; Phoenix, AZ; March 2008 